\title{
Lolita de Vladimir Nabokov: historia de una obsesión (fílmica)
}

\author{
KATIXA AGUIRRE MIGUÉLEZ
}

Euskal Herriko Unibertsitatea País Vasco

España

Resumen. El presente artículo trata de demostrar la simbiosis existente entre la novela Lolita y el arte cinematográfico. No sólo por las dos adaptaciones de las que ha sido objeto la novela de Vladimir Nabokov, sino también por las propias características estilísticas y narrativas de la novela, plagada de referencias y recursos puramente cinematográficos. Recurso clave durante toda la novela, la técnica cinematográfica se convierte en el mejor aliado del narrador no fiable Humbert Humbert- en su lucha por dominar a Lolita y manipular al lector. Para finalizar, se intenta demostrar una afinidad perpetua entre el personaje tipo de Lolita y el cine, especialmente el de Hollywood.

Palabras clave: cine, literatura, Lolita, Nabokov, imaginario

\begin{abstract}
The present paper intends to reveal the virtual symbiosis between the novel Lolita and cinematic art since the book was published. Not only with respect to of the two adaptations Hollywood has produced of Vladimir Nabokov's Lolita, but also with respect to the inner features of the novel, rich in filmic references and resources. In fact, cinematographic technique is a key tool and an ally for the unreliable narrator Humbert Humbert happens to be. Likewise, an affinity between the Lolita type character and the cinema (especially Hollywood cinema) will be exposed.
\end{abstract}

Keywords: cinema, literature, Lolita, Nabokov, imaginary 
Vladimir Nabokov escribió Lolita, su obra más importante y novela capital del siglo $\mathrm{XX}$, en los Estados Unidos, entre finales de la década de los cuarenta y principios de los cincuenta. Hablamos pues de la inmediata posguerra, tiempo de baby-boom y auge de la cultura pop, y más relevantemente, época en la que el cine de Hollywood ya ha conformado todo un imaginario social que supera con creces el imaginario literario hegemónico durante todo el siglo anterior. Leyendo Lolita resulta admirable que Nabokov, a pesar de su condición de distinguido emigré y elitista confeso, ajeno en principio a la cultura de masas, supiera hacerse eco de una manera tan vívida del poder de Hollywood sobre el imaginario colectivo. Pero así es. Lolita y Hollywood se han entendido (y peleado) desde siempre. Dicha afinidad queda patente en muy diversas facetas.

Por un lado, la novela contiene numerosísimas referencias cinematográficas, así como recursos estilísticos más propios del arte cinematográfico que del literario. Es precisamente el recurso cinematográfico una de las técnicas más recurrentes con las que el narrador no fiable Humbert Humbert articula su discurso artificioso. De la misma forma, no podemos olvidar el interés que despertó la novela Lolita en Hollywood nada más publicarse. No en vano, Stanley Kubrick y su colaborador James B. Harris compraron la primera opción sobre los derechos de la novela en 1958, el mismo año en que se publicó ésta en los Estados Unidos. A mediados de los noventa, Hollywood giró su mirada de nuevo hacia la polémica novela para realizar una nueva adaptación de la mano de Adrian Lyne. Para entonces, el epíteto Lolita se había extendido ya a casi cualquier actriz pubescente que apareciera en pantalla junto a un hombre adulto. Así pues, cuando hablamos de Lolita y Hollywood, cabe hablar de una suerte de simbiosis, casi una obsesión mutua.

Toda la obra de Nabokov en general, y Lolita en particular, ha sido descrita como plástica y colorida, muy cercana a las características cinematográficas, donde el sentido privilegiado es siempre la vista. Las descripciones de sonidos y movimientos, los flash-backs y flash-fordwards, el fundido a negro, la cámara lenta... todo eso está en la escritura de Nabokov, hasta el punto de que sus novelas han sido consideradas películas en prosa (Kimmel, 1988). Y en Lolita esta característica está llevada a su 
extremo. Por un lado Nabokov quiere "inventar Norteamérica", como él mismo confiesa en el epílogo Sobre un libro llamado "Lolita", y qué mejor manera de hacerlo que fotografiándolo a la manera fílmica. Por otro se puede argumentar que tratándose Humbert de un narrador tan poco fidedigno, un narrador que busca embaucar al lector y disfrazar con su prosa hipnótica y sofisticada la naturaleza cruel y malvada de su relación con Lolita, el filtro del cine puede ser el que más se adecúa a la mirada grotesca, distorsionada y artificiosa de Humbert. Por lo tanto Nabokov sabe perfectamente que el cine supone una "segunda mirada" manipulada en extremo, que no es de fiar, y por eso la elige y la explota al máximo.

Alfred Appel muestra en su libro Nabokov's Dark Cinema que la obra de Nabokov y muy especialmente Lolita está repleta de referencias a las imágenes de la cultura popular: el cómic y sobre todo el cine (1974: 3). Estas referencias son tanto estructurales como temáticas. El día a día en Lolita está, efectivamente, influenciado por el cine. Ya desde el principio Humbert se lamenta del pobre sucedáneo que supone el portazo que le da a su ex mujer, Valechka, frente al revés en la mejilla que debería haberle dado "según las normas del cinematógrafo" (pág. 37) ${ }^{1}$. Cuando conoce a Charlotte Haze ésta le parece una "mala copia de Marlene Dietrich" (pág. 45) y sueña con escapar a las "playas en technicolor" (pág. 44) en lugar de quedarse en la triste ciudad de Nueva Inglaterra a la que es destinado. Las esperanzas de Humbert de conseguir a Lolita nacen cuando cae en la cuenta de que la pequeña Dolores es una "ávida lectora de revistas cinematográficas" y que seguramente le dejará besarla si él algún día se atreve a intentarlo, y además presume que la niña cerrará los ojos "como enseña Hollywood" (pág. 57). De la misma manera, Humbert se mira al espejo y se encuentra cierto parecido con un actor del que Lolita parece estar enamorada, lo que aviva sus esperanzas de conseguir a su amada (pág. 43).

El cine, pues, condiciona y enseña actitudes, brinda un modelo de comportamiento y ofrece un reverso en el que la vida corriente se mira haciendo que la

\footnotetext{
${ }^{1}$ Las citas de la novela Lolita están tomadas de la edición española publicada por Anagrama en 1991, con traducción de Enrique Tejedor. Cuando junto al número de la página aparezca la inscripción AnLo la cita está tomada y directamente traducida de la edición original de Lolita editada por Alfred Appel.
} 
comparación resulte siempre desalentadora. No sólo para Humbert, también para Lolita: ella busca un galán de Hollywood y acaba a expensas de un profesor cuarentón.

Se diría que Humbert el escribiente (recordemos que la novela toma la forma de una confesión escrita por el reo Humbert) incluso tiene envidia de la técnica cinematográfica. Explicando la muerte de Charlotte, madre de Lolita, el pedófilo profesor se lamenta de tener que "traducir en una secuencia de palabras el impacto de una visión instantánea" ya que eso "desfigura el verdadero fogonazo, la indisoluble univocidad de mi impresión” (pág. 109). Al ver por vez primera a Lolita, Humbert confiesa que le es "muy difícil explicar con la fuerza adecuada esa llamarada, ese estremecimiento, ese impacto de apasionada anagnórisis" (pág. 48). Aunque en la traducción que manejamos en este trabajo la frase se ha perdido, cuando Humbert pasa por delante de Lolita por primera vez lo hace "disfrazado de adulto, un gran pedazo de hombría cinematográfica" (AnLo 39). Es decir, como un actor interpretando el papel de hombre.

Además de eso Humbert y Lolita jalonan sus viajes con frecuentes visitas al cinematógrafo: "vimos, voluptuosamente, sin discriminación, ciento cincuenta o doscientas películas sólo durante ese año" y "llegamos a ver una película hasta media docena de veces" (pág. 187). Y todo eso a pesar de las dificultades con las que se encuentra Humbert en la sala de cine cuando al rodear "inocentemente con mi brazo los hombros de Lo" y aproximar "mi mandíbula a su sien" percibe a "dos harpías" que empiezan a "murmurar las cosas más extrañas" (pág. 188). Es evidente que a Lolita le fascina el cine, el propio Humbert se queja de que Lolita prefiera la más tonta de las películas al "país maravilloso que yo le ofrecía" (pág. 182); pero a Humbert también es un entretenimiento que le conviene. Le conviene en tanto sirve de evasión para su Lolita cautiva (pan y circo, para que la niña no se rebele) y porque siempre que no haya harpías espiándolo puede aprovecharse de la oscuridad y la intimidad de la sala de cine para un contacto físico con Lolita. Eso sí, Humbert puntualiza: “mientras durara mi régimen, nunca, nunca le permitiría ir con un joven en celo al cinematógrafo" (pág. 204). No es sólo la técnica cinematográfica lo que Humbert utiliza como instrumento de 
poder, las propias proyecciones de películas le sirven para mantener su dominación sobre Lolita.

La idea del carácter fílmico de las novelas de Nabokov está bien extendida. Quizá por ello las novelas de Nabokov no son extrañas al cine. Hasta hoy doce novelas del escritor han sido adaptadas, con mayor o menor repercusión, a la pantalla. La última en presentarse en pantalla grande ha sido La Defensa Luzhin (The Luzhin Defence, Marleen Gorris, 2000). La primera y más famosa fue Lolita (Stanley Kubrick, 1962), que en 1997 tuvo otra oportunidad de trasladarse a la pantalla de manos de Adrian Lyne (Lolita, 1997).

Por supuesto, nada tiene de insólito que el cine gire su cabeza a la literatura, de hecho, se calcula que la mitad de las películas comerciales que se estrenan al año tienen un origen literario e incluso hay quien afirma que el número de adaptaciones supera al de guiones originales (Jenkins, 1997: 5). En su ansia por encontrar historias, los estudios de Hollywood rastrean las bibliotecas incansablemente en busca de material original que trasladar a la pantalla. Algunos derechos son comprados incluso antes de que la obra literaria se haya comercializado. No es de extrañar por lo tanto que Lolita, considerada una de las mejores y más originales novelas del siglo $\mathrm{XX}$, haya sido adaptada al cine no una, sino dos veces

La Lolita de la novela, a quien Humbert llama starlet, sueña con triunfar en Hollywood y allí es donde tanto Humbert como Quilty, sus dos amantes adultos, prometen llevarla. El primero incluso llega a poner rumbo a California, pero sólo porque planea cruzar la frontera con México y vivir al otro lado sin interferencias de la justicia estadounidense. La promesa hollywodiense del segundo se reduce a alguna que otra grabación de cine pornográfico, no precisamente en la meca del cine, sino en un rancho perdido de nombre Duk Duk. El sueño cinematográfico de Lolita, por lo tanto, se queda en nada. "Creo que la pobre chiquilla impetuosa pensaba que con sólo cincuenta dólares en el bolso podría llegar a Hollywood" (pág. 202) se jacta un cruel Humbert de los planes de huída de la nínfula, que, por supuesto, nunca llegan a consumarse. 
Lolita es un personaje muy adecuado a la pantalla, y así lo corrobora el narrador Humbert en la novela, quien, a través de numerosas metáforas visuales y particularmente cinematográficas, coloca a Lolita de lleno en el centro de la representación visual. En cierto sentido, Lolita va a pasar a convertirse en la estrella principal de una película que Humbert está produciendo y dirigiendo. Si comparamos el tratamiento de los dos grandes amores en la vida de Humbert Humbert, esto es, su amor perdido de adolescencia y pretendido causante de su pedofilia, Annabel, y Lolita, el tratamiento visual y el continuo intento de colocar a Lolita bajo focos y cámaras se hace aún más evidente. Así lo describe el propio Humbert:

\begin{abstract}
Hay dos clases de memoria visual: con una, recreamos diestramente una imagen en el laboratorio de nuestra mente con los ojos abiertos (y así veo a Annabel, en términos generales tales como "piel color miel", "brazos delgados", "pelo castaño y corto", "pestañas largas", "boca grande, brillante"); con la otra evocamos instantáneamente, a ojos cerrados, en la oscura intimidad de los párpados, el objetivo, réplica absolutamente óptica de un rostro amado, un diminuto espectro de colores naturales (y así veo a Lolita). (pág. 18)
\end{abstract}

Cuando Humbert recrea a Annabel, lo hace por partes, de una manera descriptiva, con los ojos abiertos: lo hace a la manera literaria. Cuando recuerda a Lolita lo hace instantáneamente, con un golpe de vista, con los ojos cerrados para que sus párpados sirvan de pantalla, en esa "oscuridad íntima” que podría ser perfectamente la de la sala de cine. Annabel tiene incluso nombre literario, y remite indefectiblemente a la Annabel Lee del famoso poema de Edgar Allan Poe; y como Poe, Humbert también la conoce en unas vacaciones junto al $\operatorname{mar}^{2}$. En la única foto que Humbert posee de Annabel, ésta "no salió bien (...) en la soleada bruma donde se diluyó su encanto" (pág. 19). Su representación plástica es por lo tanto imposible: Annabel pertenece al ámbito de la literatura y sólo mediante el artificio literario podrá ser resucitada y recreada.

Con Lolita pasa exactamente lo contrario. Literalmente Humbert llega a decir que ella "no es la niña frágil de una novela femenina" (pág. 53) sino que más bien

\footnotetext{
${ }^{2}$ It was many and many a year ago / in a kingdom by the sea / that a maiden there lived whom you may know / by the name of Annabel Lee; / and this maiden she lived with no other thought / than to love and be loved by me. I I was a child and she was a child / In this kingdom by the sea; / but we loved with a love that was more then a love- / I and my Annabel Lee; / With a love that winged seraphs of heaven / coveted her and me. Edgar Allan Poe, 1849. Humbert cambia el Kingdom (reino) por Princedom (principado), donde conoce a Annabel.
} 
actuaba "como joven campeona en una película" (pág. 253). Si Humbert cierra los ojos no ve "sino una fracción de Lo inmovilizada, una imagen cinematográfica" (pág. 52). Las palabras no alcanzan para describir a Lolita y por lo tanto Humbert se lamenta, una vez que la ha perdido, de no haberla filmado, y llora porque sólo puede "jugar con palabras" (pág. 40), con la desventaja de que él no es "un poeta, sólo un registrador muy consciente" (pág. 81), es decir, un mero camarógrafo que filma lo que ve. Y sin embargo, sin la literaria Annabel no hubiera podido existir la cinematográfica Lo. Annabel es el "prototipo" de Lolita, a quien ésta "llegaría a eclipsar" (pág. 48).

Humbert es, además, un reconocido voyeur, ya que antes de conocer a Lolita se limita a espiar a todas las nínfulas que se cruzan por su camino. De hecho, es Lolita la primera nínfula con la que tiene contacto físico, después de observar concienzudamente y durante años a sus pequeños objetos de deseo en parques y calles. Y esto no ocurre hasta la página 145 de la novela: antes de ser actor Humbert no es más que un director. Así, dice que reconocer a la nínfula entre un grupo de niñas es una cuestión de "ajuste focal, de cierta distancia que el ojo interior supera contrayéndose” (pág. 24) y trata de percibir a Lolita "debidamente enfocada" (pág. 51). Después confiesa que pasa la tarde "proyectando, dirigiendo mi experiencia de la mañana" (pág. 71) con la sensibilidad propia de un director de cine, que, tras un día de rodaje, examina el material en bruto.

Pero algo indudablemente perverso subyace en la obsesión de Humbert por registrar y dirigir a Lolita. Si es Humbert quien le da el espacio de representación evidentemente es Humbert también quien controla en todo momento los movimientos de la nínfula. Lolita es la actriz principal de una película que Humbert está construyendo. Y tocamos así un aspecto clave: el poder de la mirada. Y qué es sino un asunto de poder cualquier relación Humbert-Lolita que se haya podido dar a través de los tiempos. Humbert es, según sus palabras, un registrador muy consciente. Descripción que implica, a primera vista, un aura de inocente neutralidad e intervención mínima: él es en principio un voyeur, él capta lo que está allí, la magia letal de las nínfulas primero, el poder destructivo de Lolita después, que aunque desapercibido para el común de los mortales se hace evidente para un "loco, un poeta" como él. La frase "no me interesa en absoluto el llamado sexo (...). Una tarea más importante me 
reclama: fijar de una vez por todas la peligrosa magia de las nínfulas" es toda una declaración de intenciones. Él ve lo que otros no ven, y para mostrarle al mundo eso que para el común de los mortales está oculto utiliza una y otra vez las metáforas cinematográficas.

No obstante, Humbert parece querer obviar que no hay nada más manipulado que una imagen cinematográfica. Lo que el espectador ve no es sino un complejo artificio que recrea la realidad, una realidad que antes ha sido acotada, filtrada, editada, segmentada, desordenada y vuelta a ordenar. Y, sin embargo, sólo a través de esta construcción incesante se crea la ilusión de imagen realista, de espejo de la realidad. Humbert no es sólo un registrador: él localiza, encuadra, enfoca, ilumina, graba, corta, edita y proyecta a Lolita. En realidad, la metáfora cinematográfica le sirve a Humbert para disfrazar de amor lo que no es sino una obsesión, una fijación patológica. $\mathrm{Su}$ mirada sobre Lolita es una "segunda mirada" como lo es cualquier mirada en el cine (Colaizzi, 1995: 19). Humbert es el portador de la mirada, y por tanto ostenta el poder. Lolita no es sino la receptora de la mirada y el soporte del deseo de Humbert.

Sin embargo Humbert empieza a perder poder cuando de observador/director pasa a actor. Los dos grandes viajes por carretera que describe la novela dan cuenta de esa pérdida de poder: en el primero Humbert guía a Lolita, en el segundo Lolita va marcando en un estudiado mapa los trayectos por los que Humbert deberá llevarla. Pero no porque la niña haya conseguido coger las riendas, sino más bien porque Lolita está ahora sujeta a otra mirada, la del otro personaje masculino, Clare Quilty, que sin ser director de cine, tiene un oficio similar: es dramaturgo, creador de una obra (Los Cazadores Encantados), de la que Lolita ha sido, literalmente, protagonista. Es Quilty quien está indicando a Lolita por dónde deben conducirse. Incluso de una manera literal, también Quilty quiere hacer de director, instando a Lolita a que participe en un proyecto pornográfico que él mismo quiere grabar en su casa.

Cuando todo ha acabado y Humbert ha perdido a Lolita, éste se lamenta “¡Idiota, triple idiota! Pude haberla filmado, ahora estaría conmigo, ante mis ojos, en la sala de proyecciones de mi dolor y mi desesperación” (pág. 251) refiriéndose, claro está, a una nínfula que por su propia naturaleza es efímera y perecedera, y por lo tanto sólo puede 
mantenerse por siempre joven, por siempre fresca, bajo el hechizo del celuloide. Recordemos que a Humbert le atormenta la idea de que Lolita vaya a crecer: "Sabía que me había enamorado de Lolita para siempre, pero también sabía que ella no sería siempre Lolita. El uno de enero cumpliría trece años. Dos años más y habría dejado de ser una nínfula para convertirse en una jovencita y después, en una muchacha, ese colmo de horrores."

No es por lo tanto descabellado afirmar que el cine es el medio natural de Lolita, su elemento, su idioma particular mediante el cual Humbert podrá levantar barricadas contra el paso del tiempo, crear la ilusión de eternidad. El medio cinematográfico es a la vez la metáfora del fracaso de Humbert y también la encarnación de su deseo de hacer de Lolita inmortal y por siempre joven.

Esta obsesión por el paso del tiempo y por mantener la juventud a toda costa es un fenómeno que se extiende a todo producto cinematográfico y que afecta especialmente a las mujeres. Jackie Stacey (1994: 120) señala que se trata éste de uno de los fenómenos más reseñable con respecto a los ideales femeninos y masculinos representados en pantalla. Para esta autora hay una gran variedad de ideales masculinos en contextos concretos, y que varían a través de la historia y el paso del tiempo. Esta idea contrasta con el ideal de feminidad deseable, menos variado y más estanco, más repetitivo, y que siempre ha sido construido como juvenil y por tanto, muy dado al deterioro del paso del tiempo. Stacey señala que el muy pequeño porcentaje de personajes femeninos que están por encima de los cuarenta años en el cine de Hollywood, es indicativo de que una feminidad por encima de esa edad no resulta deseable. Los valores actuales giran continuamente en torno a la juventud, el valor social más apreciado y valorado. Así podemos observarlo no sólo en el cine, sino en la publicidad (difícil ver a una actriz madura si no es para promocionar productos relacionados, por ejemplo, con la menopausia) en la moda (las modelos menores de edad no son excepción, sino más bien la regla), en la televisión... donde todo parece estar encaminado a evitar el envejecimiento.

Que la naturaleza de Lolita y la del propio cine coinciden en multitud de aspectos lo ratifica también la historia del séptimo arte. Antes de Nabokov ya había 
Lolitas, si bien no eran identificadas con ese nombre, pero ya entonces tenían en la gran pantalla su plataforma de exhibición privilegiada. Así pues, Lolita no surgió ex nihilo de la mano de Nabokov, ni Hollywood tuvo que recibirla como a una recién llegada. Antes de que la novela Lolita fuera siquiera escrita, numerosas proto-Lolitas rondaban ya los platós cinematográficos y los despachos de los productores. Los escándalos más sonados y recurrentes de Hollywood implican invariablemente, ya desde la etapa del cine mudo, a un hombre maduro con una jovencita, llámese ese hombre Charles Chaplin, Errol Flyn o Roman Polanski. Paralelamente a estos castings y escándalos carne de papel cuché, las pantallas dieron vida a innumerables personajes de niñas prepubescentes irreprochablemente castas primero, involuntariamente seductoras luego y abiertamente fatales finalmente.

Prototipos de Lolita los hay ya en los primeros rollos de cine mudo, lo que nos lleva a refrendar las palabras de Marianne Sinclair (1988: 5) cuando dice que Lolita es joven por definición, pero al mismo tiempo, tan vieja como el propio cine. Estas protoLolitas de comienzos del siglo XX no eran sino personajes directamente heredados de la literatura victoriana del siglo XIX que tan bien había explotado el cliché: heroínas dickensianas desvalidas y necesitadas de un padre protector que bajo el aspecto de inocencia infantil escondían el atractivo más irresistible.

David Wark Griffith, pionero al que el cine le debe la categoría de arte, era él mismo un victoriano en toda regla. Admirador de Edgar Allan Poe del que llegó rodar una biopic (a quien, por cierto, también rinde homenaje Humbert, al recordar a los lectores que el objeto de deseo del divino Edgar era una niña de catorce años), su primera película tiene por título Las aventuras de Dolly (The Adventures of Dolly, 1908) y ya contiene las claves narrativas de casi todos sus films: la huerfanita desafortunada que cae en manos, alternativamente, de hombres de gran corazón o gran crueldad. Así, una de sus actrices preferidas, Lilian Gish, es brutalmente golpeada en Lirios Rotos (Broken Blossoms, 1919) o consigue escapar por los pelos de una violación en El Nacimiento de una Nación (Birth of a Nation, 1915). Los atacantes (por cierto, casi siempre asiáticos o negros) solían verse enfrentados a jóvenes de tez blanca y corazón puro que salvaban en el último momento a la pobre niña desvalida. 
Gladys Mary Smith, conocida como Mary Pickford, trabajó por primera vez con Griffith cuando ya había cumplido los dieciséis años pero su carrera de actriz se alargó casi veinte años más en los que nunca abandonó los papeles de niña inocente. Pickford es hoy reconocida como la primera actriz en conformar el star system. Hasta entonces los actores y actrices no aparecían en los créditos de las películas con lo que el público, para reconocer a los actores que les caían en gracia, se fijaban en alguna característica física. Mary Pickford fue enseguida identificada y demandada por la audiencia como la "la chica de los tirabuzones". Fue la primera actriz con estatus de estrella tal y como lo conocemos hoy: cachés elevados y promociones que giraban en torno a ella. En 1919 fundó junto a Douglas Fairbanks, Charles Chaplin y el propio D.W. Griffith la productora United Artists, convirtiéndose en una de las primeras y más poderosas mujeres productoras de Hollywood.

Pero mientras eso ocurría fuera de la pantalla Mary Pickford era para las audiencias la niña eterna y la "novia de América". Gracias a su baja estatura y unas poses infantiles muy bien ensayadas no era difícil recrear en esta adulta la imagen de una tierna niña. Para Bret Wood se trataba de encubrir el atractivo de la mujer adulta envolviéndola en un "sentimental lucimiento de jocosidad infantil, que estimulaba las fantasías románticas más puras del espectador, disipando la ansiedad del adulto" (Wood, 1994: 33). Por lo tanto, encubrir una sexualidad obvia en cualquier mujer adulta bajo la idea de la inocencia y la pureza infantil, tal y como ocurriera en la época victoriana en los campos de la pintura y la incipiente fotografía, una imagen frente a la que el hombre adulto puede sentirse seguro y no amenazado. Siguieron la estela de Mary Pickford, aun sin alcanzar su colosal fama, actrices como la primera actriz de Griffith, Lilian Gish, la protagonista de comedias Mabel Normand, y la más oscura Mary Miles Minter, involucrada más tarde en el asesinato del director y supuesto Humbert, William Desmond Taylor. Todas cumplían, en la temprana época del cine mudo, el mismo papel: encarnar en la pantalla la inocente y nada sofisticada imagen de la niña incorrupta.

Mary Pickford jamás consiguió desembarazarse de la imagen niña inocente y pura, y su carrera como actriz se vio reducida a estos papeles, precipitándose al fracaso 
cuando se aventuraba a interpretar papeles más acordes con su edad. En 1925 la revista Photoplay lanzó la siguiente pregunta a sus lectores: ¿Qué papeles le gustaría que interpretara Mary Pickford? Las respuestas fueron: Heidi, Cenicienta, Alicia en el país de las maravillas, Caperucita Roja... Pickford recibió la noticia con desesperanza, pues a la sazón contaba ya con treinta y dos años (Walker, 1972).

Si Mary Pickford era la mujer que interpretaba papeles de niña, a Shirley Temple, la estrella infantil por excelencia de la época dorada de Hollywood, le tocó ser la niña que interpretó papeles de mujer. Situada históricamente en los años treinta, cuando la censura, un incipiente código Hays y los primeros pasos de la Legión de la Decencia (que se instituyó en 1933) empezaban a hacer estragos en todo producto hollywoodiano y el cine servía de evasión para todos aquellos atenazados por la crisis económica tras el crack del 29, Shirley Temple atrajo la mirada de la audiencia, especialmente de hombres adultos que la adoraban y apreciaban su candor e inocencia. El fenómeno de la niña-estrella protagonista de películas para adultos más que de niños había comenzado. Junto a ella cabe destacar también a Jane Wither, que hacía a menudo de antítesis de la dulce Shirley, o a Margaret O’Brien, que en ocasiones rivalizó en popularidad con aquélla.

Había pasado ya la época de la actriz pre-código: los tiempos dorados de Mae West, Jean Harlow..., (“illevas una pistola en el bolsillo o es que te alegras de verme?”) que interpretaban papeles de mujeres independientes, voluptuosas, agresivas y no necesitadas de la protección del hombre, prototipos perfectos de mujer vamp que amenazaban al género masculino en general. Se imponía un "lavado de imagen de la mujer" que como toda tendencia represiva traía consigo reacciones y desviaciones veladas (Haskell, 1987:123). Se volvía pues a lo puro, lo primigenio, los añorados tiempos dorados, como ocurriera en la Inglaterra decimonónica tras la primera ola feminista y el alarmante auge de la new woman. Los Estados Unidos, entre guerras mundiales y depresiones económicas, perdían su inocencia y anhelaban recuperarla a través de la figura de la niña encantadora. Esta atmósfera sumada a la ambición sin límites de la madre de la pequeña Shirley, que aseguró haber preparado a su hija para el estrellato incluso cuando aún se encontraba en su vientre, hicieron el resto. 
Shirley Temple, la niña de los rizos de oro, aparecía en las pantallas como un ángel tierno y candoroso que ablandaba los corazones de galanes adultos. Ella era el "refugio sentimental y el alivio" para la América abrumada por la depresión (Haskell, 1987: 123). Fue una estrella en toda regla desde su primer éxito en el musical de la Fox Stand Up and Cheer (1934). En la cumbre de su carrera la pequeña Shirley podía llegar a ganar 9.000 dólares a la semana, una cifra superior a la de la mayoría de estrellas adultas de Hollywood y sus películas fueron las más taquilleras durante cuatro años consecutivos. ¿La razón de su éxito? La repetición hasta la extenuación de parámetros de comprobada fiabilidad. El argumento de las películas de Shirley Temple, films que se construían especialmente para ella y su lucimiento, era similar y recurrente. Una pequeña y adorable niña, huérfana y solitaria, encontraba a un varón adulto de buen corazón que acababa haciéndose cargo de ella. La niña se enamoraba (castamente) de su benefactor, y éste se resistía hasta que su corazón se ablandaba y le correspondía (también castamente). Todas sus películas incluían una escena obligatoria en la que la pequeña Shirley se subía al regazo del galán de turno y conseguía derretir toda resistencia que el hombre hubiera puesto en un principio.

Fue Graham Greene el primero en levantar la voz sobre un asunto espinoso y que se debatía en la frontera entre la admiración casta y la atracción erótica. Para Greene la infancia en Temple era

un disfraz, su atractivo es más secreto y más adulto... Vean como mide a un hombre con ojos ágiles, con sus hoyuelos depravados. Las emociones adultas de amor y dolor cruzan por la máscara de la niñez. Sus admiradores, hombres y sacerdotes de mediana edad, responden a su indudable coquetería, ante la visión de su pequeño cuerpo bien formado y deseable, envuelto en una enorme vitalidad, sólo porque la cortina de seguridad de la historia y el diálogo cae entre su inteligencia y su deseo ${ }^{3}$.

Greene se refería aquí a la interpretación de Temple en al película La Mascota del regimiento (Wee Willie Winkie, John Ford, 1937) que él consideraba erotizada de una manera poco apropiada para una niña. La lúcida crítica del novelista fue respondida con una demanda judicial y los abogados de Temple consiguieron ganar el caso por ultraje. Se trataba de denunciar la explotación a la que la pequeña estaba siendo sometida y el

\footnotetext{
${ }^{3}$ Citado en Wood, Bret. "Lolita Syndrome" ibid. idem
} 
denunciado fue, paradójicamente, el propio Graham Greene. La sentencia consiguió arruinar la revista semanal británica Night and Day que había publicado el polémico artículo, y Greene (por aquel entonces un escritor sin demasiados recursos económicos) tuvo que pagar 1500 libras por daños y perjuicios (Baxter, 1999).

Mary Pickford y Shirley Temple son dos ejemplos paradigmáticos de lo que la magia del cine hace por las nínfulas: sin son mujeres las convierte en modelos de ternura e inocencia infantil, y si se trata de niñas explota en ellas una coquetería sensual y alarmantemente precoz. La carrera de Pickford como niña-actriz acabó a los 32. La de Shriley Temple estuvo prácticamente finiquitada a los 12 . Y a pesar de las diferencias ambas son las dos caras de la misma moneda. La una es demasiado joven, la otra es demasiado mayor, su atractivo no causa ansiedad, y sin embargo atrae por la misma razón. Julie Burchill lo argumenta sin ambages. Toda actriz de Hollywood, si es deseable, es por definición joven (Burchill, 1986: 122).

Mary Pickford podría colocarse en una primera fase en el desarrollo de las nínfulas cinematográficas: se trataba de una mera translación de las heroínas decimonónicas literarias a la pantalla (Dickens, las hermanas Brönte...), dechados de virtud y candor. Shirley Temple supondría una segunda fase en el devenir de la historia del cine, en la que la pequeña se muestra más abiertamente seductora, pero sin ser aún consciente de su poder erótico. Pero la Segunda Guerra Mundial dejó al descubierto demasiadas cosas como para que el público siguiera creyendo en pequeños angelitos del estilo de Shirley Temple o Deanna Durban. Y llegó la tercera fase, bautizada por Nabokov y encarnada por Lolita, tal y como se la conoce hoy, voluptuosa y consciente de su poder, manipuladora y controladora. Más que una víctima del hombre adulto, la culpable de todas sus desgracias. No tan joven, pero apelando a su infantilidad una y otra vez. Más que una femme fatale, una fille fatale.

En este contexto histórico se enmarca la novela Lolita, amparándose en la popularidad de los personajes femeninos pubescentes y en la curiosidad que comenzaban a levantar temas como la sexualidad infantil, espinosa cuestión del que Nabokov se mofa cuando Humbert es convocado a una entrevista con la tutora de Lolita y ésta le comenta que la niña "aún vacila entre la zona anal y genital de desarrollo" 
(pág. 212). Desde entonces hasta nuestros días, el fenómeno no ha hecho sino ampliarse, siendo el arquetipo de Lolita la más común forma de representar la sexualidad femenina adolescente en casi cualquier expresión de la cultura mediática contemporánea.

Lolita es, pues, una novela surgida paradójicamente desde un imaginario cinematográfico y destinada a alimentar ese propio imaginario. Una novela que pedía la imagen y que en el cine ha encontrado su trampolín de popularidad y su hábitat ideal.

\section{Referencias bibliográficas}

Appel, A. (1974). Nabokov's Dark Cinema. New York: Oxford University Press.

Baxter, J. (1999). Stanley Kubrick: Biografía. Madrid: T\&B editores.

Burchill, J. (1986). Girls on Film. London: Virgin Books.

Colaizzi, G. (ed.) (1995). Feminismo y teoría fílmica. Valencia: Ediciones Episteme.

Haskell, M. (1987). From Reverence to Rape. The Treatment of women in the movies.

Chicago: University of Chicago Press. $2^{\text {nd }}$ edition, [Primera edición: 1973]

Jenking, G. (1997). Stanley Kubrick and the art of adaptation: three novels, three films.

Jefferson, North Carolina: McFarland \& Company.

Kimmel, L. (1988). The Cinematography of Nabokov's creative vision. Obtenido el 22-1-2008 desde http://www.geocities.com/Athens /3682/nabokov.html

Nabokov, V. (1991). Lolita. Barcelona: Anagrama.

Penguin Classics.

(2000) The Annotated Lolita. Ed. Alfred Appel Jr. London:

Sinclair, M. (1988). Hollywood Lolita: The Nymphet Syndrome in the Movies, London: Plexus Publishing, Limited.

Stacey, J. (1994). Star Gazing: Hollywood Cinema and Female Spectatorship. London and New York: Routledge.

Walker, A. (1972). El sacrificio del celuloide. Aspectos del sexo en el cine. Barcelona:

Anagrama. [Ed. Original The celluloid sacrifice: aspects of sex in the movies, 1967]

Wood, B. (1994). Lolita syndrome. Sight\&Sound , 4(6), 32-34

(Artículo recibido: 30-03-2010; revisado: 31-05-2010; aceptado: 19-06-2010) 